\title{
Optimization of N Content for Higk- $k$ LaTiON Gate Dielectric of Ge MOS Capacitor
}

\author{
H. X. Xu, J. P. Xu ${ }^{*}$, C. X. Li, L. Liu, P. T. Lai", C. L. Chan
}

\begin{abstract}
Thin LaTiON gate dielectric is deposited on Ge (100) substrate by reactive co-sputtering of $\mathrm{La}_{2} \mathrm{O}_{3}$ and $T i$ targets under different $A r / N_{2}$ ratios of 24/3, $24 / 6,24 / 12$, and $24 / 18$, and their electrical properties are investigated and compared. Results show that the LaTiON gate-dielectric Ge MOS capacitor prepared at an $A r / N_{2}$ ratio of $24 / 6$ exhibits highest relative permittivity, smallest capacitance equivalent thickness, and best electrical characteristics, including low interface-state density, small $C-V$ hysteresis and low gate leakage current. This is attributed to the fact that a suitable $N$ content in LaTiON can effectively suppress the growth of low- $k$ $\mathrm{GeO}_{\mathrm{x}}$ interfacial layer between LaTiON and Ge substrate.
\end{abstract}

\section{INTRODUCTION}

As Si-based metal-oxide-semiconductor field-effect transistor (MOSFET) is approaching its limit, germanium MOSFETs with high relative permittivity (high $k$ ) gate dielectrics are extensively discussed as alternative candidates for future CMOS technology. $\mathrm{La}_{2} \mathrm{O}_{3}$ is considered as one of the most promising high- $k$ materials due to its large bandgap (5 6 eV) [1-2], relatively large $k$ value $(\sim 25)$ [2-4], high electrical breakdown field strength and good thermal stability [1, 5] when contacting with $\mathrm{Si}$. Recently, it was reported that $\mathrm{La}_{2} \mathrm{O}_{3}$ thin film also showed many advantages when contacting with $\mathrm{Ge}$, including low interface-state density, very small frequency dispersion and hysteresis due to formation of a stable lanthanum germanate [6-8]. However, a relatively low permittivity for lanthanum germanate due to $\mathrm{Ge}$ diffusion into high- $k$ dielectric prevents further decrease in equivalent oxide thickness [7].

Ti addition has been studied by several groups to increase the permittivity of Hf-based oxide because of the extremely high relative permittivity of Ti-based oxides ( 80) [9-10]. Higher permittivity has been obtained with

J. P. Xu, H. X. Xu and L. Liu are with the Department of Electronic Science \& Technology, Huazhong University of Science and Technology, Wuhan 430074, People's Republic of China. ${ }^{*}$ E-mail: jpxu@mail.hust.edu.cn

P. T. Lai, C. X. Li and C. L. Chan are with the Department of Electrical \& Electronic Engineering, the University of Hong Kong, Pokfulam Road, Hong Kong.

"E-mail: laip@eee.hku.hk

H. X. Xu is also with the Department of Physics \& Electronic Technology, Huanggang Normal University, Huangzhong, 438000, People's Republic of China.
Ti increase while leading to gate leakage current increase [11]. On the other hand, $\mathrm{N}$ incorporation in $\mathrm{HfO}_{2}$ results in beneficial characteristics including reduction of gate leakage current, improved thermal stability of the dielectric material, due to suppression of the onset of crystallization [12-13]. In view of of the two effects, it is expected that good properties can be achieved by simultaneously incorporating $\mathrm{Ti}$ and $\mathrm{N}$ into $\mathrm{La}_{2} \mathrm{O}_{3}$ thin film, when suitable $\mathrm{Ti}$ and $\mathrm{N}$ contents are chosen. In this work, Ge MOS capacitors with LaTiON thin gate dielectrics deposited under various $\mathrm{Ar} / \mathrm{N}_{2}$ ratios (24/3, $24 / 6,24 / 12$, and 24/18) are fabricated and the impacts of $\mathrm{N}$ content on their electrical properties are examined. It is found that the $k$ value, interface-state density, gate leakage current and $\mathrm{C}-\mathrm{V}$ hysteresis of these MOS capacitors strongly depend on the $\mathrm{N}$ content in the LaTiON film. When $\mathrm{N}$ content is controlled at a suitable value, good electrical properties can be obtained for the MOS devices.

TABLE I

\section{PREPARETION CONDITIONS AND N CONTENT in LaTiON FILMS}

\begin{tabular}{ccccc}
\hline $\begin{array}{c}\mathrm{Ar} / \mathrm{N}_{2} \\
\text { flow } \\
\text { ratio }\end{array}$ & $\begin{array}{c}\mathrm{Ti}- \\
\text { target } \\
\text { power } \\
(\mathrm{W})\end{array}$ & $\begin{array}{c}\mathrm{La}_{2} \mathrm{O}_{3}- \\
\text { target } \\
\text { power } \\
(\mathrm{W})\end{array}$ & $\begin{array}{c}\text { physical } \\
\text { thickness } \\
(\mathrm{nm})\end{array}$ & $\begin{array}{c}\mathrm{N} \\
\text { content } \\
(\%)\end{array}$ \\
\hline $24 / 3$ & 17.4 & 30 & 7.59 & 11.5 \\
$24 / 6$ & 17.4 & 30 & 7.55 & 12.9 \\
$24 / 12$ & 17.4 & 30 & 7.62 & 13.5 \\
$24 / 18$ & 17.4 & 30 & 7.65 & 14.8 \\
\hline
\end{tabular}

Note: $\mathrm{N}$ percentage is evaluated by comparing the growth rate of LaTiON film with that of LaTiO film deposited at the same powers of $\mathrm{La}_{2} \mathrm{O}_{3}$ and $\mathrm{Ti}$ targets and the same Ar flow rate.

\section{EXPERIMENTS}

Ge substrate used was Sb-doped $n$-type Ge (100) wafers with a resistivity of $0.10 \sim 0.11 \Omega \mathrm{cm}$. The wafers were cleaned in organic solvents, and lastly with de-ionized water rinsing followed by 30 -s diluted HF (1:50) dipping for several cycles to remove the native oxide, leaving a $\mathrm{H}$-terminated surface. After drying in $\mathrm{N}_{2}$, LaTiON thin film was deposited by reactive co-sputtering of $\mathrm{La}_{2} \mathrm{O}_{3}$ and Ti targets at different $\mathrm{Ar} / \mathrm{N}_{2}$ ratios of 24/3, 24/6, 24/12, and 24/18 with fixed Ar flow rate of $24 \mathrm{sccm}$ at room temperature. The powers of $\mathrm{La}_{2} \mathrm{O}_{3}$ and Ti targets were fixed at $30 \mathrm{~W}$ and $17.4 \mathrm{~W}$, respectively, for all the $\mathrm{Ar} / \mathrm{N}_{2}$ ratios. A post-deposition annealing (PDA) was carried out in $\mathrm{N}_{2}$ ambient with a 
flow rate of $500 \mathrm{ml} / \mathrm{min}$ at $500^{\circ} \mathrm{C}$ for $5 \mathrm{~min}$. Subsequently, $\mathrm{Al}$ was evaporated and patterned by lithography as gate electrodes with an area $A=7.85 \times 10^{-5} \mathrm{~cm}^{-2}$, followed by a forming-gas annealing (FGA) at $300{ }^{\circ} \mathrm{C}$ for $20 \mathrm{~min}$. High-frequency $(\mathrm{HF}, 1-\mathrm{MHz})$ capacitance-voltage $(C-V)$ curves were measured by HP4284A precision LCR meter. Gate leakage current was measured by HP4156A precision semiconductor parameter analyzer. Physical thickness of the gate dielectrics was determined by a multi-wavelength ellipsometer and TEM.

\section{RESULTS AND DISCUSSION}

To determine the thickness and structural aspects of the LaTiON films, high-resolution transmission electron microscopy (TEM) image is taken and depicted in Fig.1 for the sample with an $\mathrm{Ar} / \mathrm{N}_{2}$ ratio of $24 / 6$. From the image, it can be found that the physical thickness of the LaTiON gate dielectric is $\sim 7.55 \mathrm{~nm}$, which is consistent with that $(\sim 7.50 \mathrm{~nm})$ measured by ellipsometer. Thus, the growth rate of the LaTiON film can be determined to be $\sim 0.5 \mathrm{~nm} / \mathrm{min}$ for the samples. It can be seen that negligible interfacial layer between the high-k dielectric and Ge substrate can be observed. This should be ascribed to the inhibiting effect of the incorporated $\mathrm{N}$ in the dielectric against $\mathrm{O}$ and $\mathrm{Ge}$ inter-diffusions, and thus suppressing the growth of interfacial layer at the surface of the Ge substrate [14].

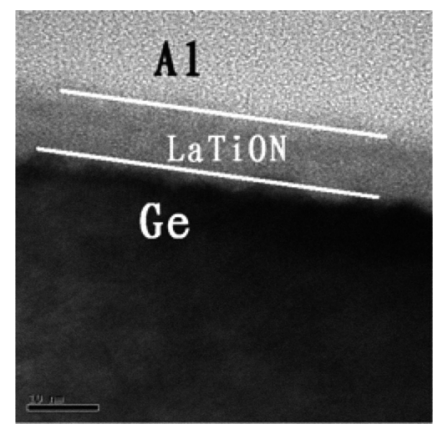

Fig. 1 TEM image of LaTiON/Ge cross section prepared at an $\mathrm{Ar} / \mathrm{N}_{2}$ ratio of $24 / 6$.

Typical HF $C-V$ curves measured at 1-MHz frequency for the LaTiON gate-dielectric MOS capacitors prepared under different $\mathrm{Ar} / \mathrm{N}_{2}$ ratios are shown in Fig. 2. The capacitor prepared at an $\mathrm{Ar} / \mathrm{N}_{2}$ ratio of $24 / 6$ exhibits the largest accumulation capacitance $\left(C_{o x}\right)$. This result suggests that the $\mathrm{N}$ content in LaTiON film prepared at the $\mathrm{Ar} / \mathrm{N}_{2}$ ratio of $24 / 6$ is optimal for suppressing the growth of low- $k$ germinate and germanium oxide on the Ge substrate. Thus, it can be reasonably speculated that the LaTiON film deposited under a high $\mathrm{Ar} / \mathrm{N}_{2}$ ratio (higher than 24/6, implying a small $\mathrm{N}_{2}$ flow rate) would give an insufficient $\mathrm{N}$ corporation in the dielectric film, and thus could not effectively block the inter-diffusions of $\mathrm{O}$ and $\mathrm{Ge}$, resulting in the formation of a thicker low-k $\mathrm{GeO}_{\mathbf{x}}$ interfacial layer. On the other hand, for small $\mathrm{Ar} / \mathrm{N}_{2}$ ratio (lower than 24/6), i.e. large $\mathrm{N}_{2}$ flow rate, a high concentration of $\mathrm{N}$ plasma species react with the $\mathrm{Ge}$ substrate and too much $\mathrm{N}$ may produce interfacial strain, giving rise to the growth of germanium oxide [15], and hence a thicker $\mathrm{GeO}_{\mathrm{x}}$ interfacial layer. Fig. 3 displays the relative permittivity $(k)$ and capacitance equivalent thickness $(C E T)$ for the samples. Corresponding to the $\mathrm{C}_{\mathrm{ox}}$, the LaTiON film deposited at an $\mathrm{Ar} / \mathrm{N}_{2}$ ratio of $24 / 6$ has the largest $k$ value and smallest $C E T$.

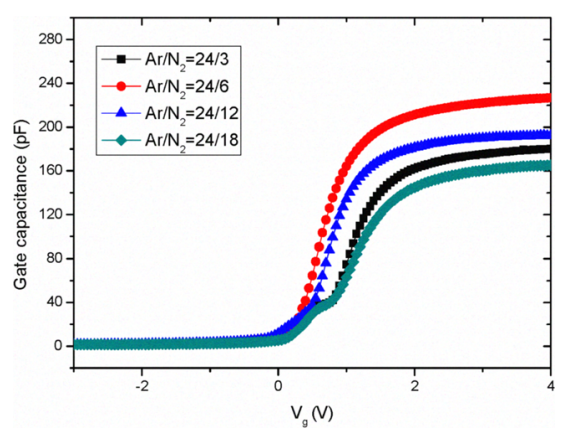

Fig. 2 High-frequency (1-MHz) $C-V$ curve of the LaTiON gate-dielectric MOS capacitors prepared at various $\mathrm{Ar} / \mathrm{N}_{2}$ flow ratios.

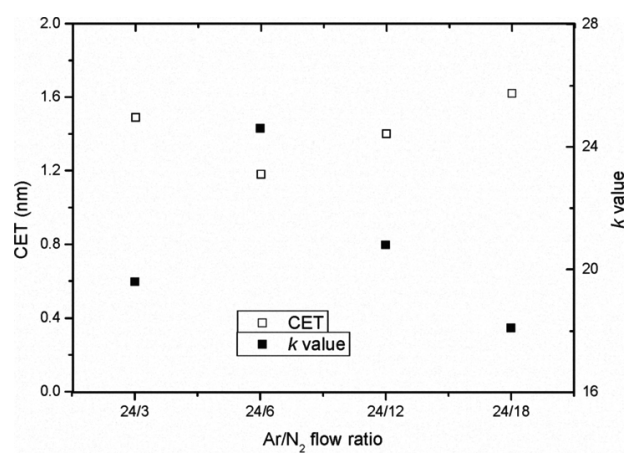

Fig. 3 Capacitance equivalent thickness (CET) and relative permittivity $(k)$ of the LaTiON gate dielectrics prepared at various $\mathrm{Ar} / \mathrm{N}_{2}$ flow ratios.

Interface-state density $\left(D_{i t}\right)$ near midgap and equivalent oxide-charge density $\left(Q_{o x}\right)$ of the LaTiON films prepared under various $\mathrm{Ar} / \mathrm{N}_{2}$ ratios are shown in Fig. 4. The flatband voltage $\left(V_{f b}\right)$ of MOS capacitor is generally determined by the metal-semiconductor work function difference and the oxide charges. The positive shift of $V_{f b}$ in the $C-V$ curves, as shown in Fig.2, is indicative of negative $Q_{o x}$ in the LaTiON gate dielectric, which probably originates from the acceptor-like interface and near-interface traps generated mainly by the Ge diffusion from the substrate to the high- $k$ layer. The larger $Q_{o x}$ 's for those LaTiON films deposited under large or small $\mathrm{Ar} / \mathrm{N}_{2}$ ratio than that deposited at an $\mathrm{Ar} / \mathrm{N}_{2}$ ratio of $24 / 6$ should be related to more acceptor-like interface and near-interface traps in their thicker interfacial layer. The $D_{i t}$ is extracted from the $1-\mathrm{MHz}$ $C-V$ curve using the Terman's method [16] for the purpose of comparison. The interface states arise from the presence of dangling bonds and/or defects at the dielectric/Ge interface. The samples prepared under small or large $\mathrm{Ar} / \mathrm{N}_{2}$ ratio introduce more defects at $/$ near the dielectric/Ge interface due to the growth of thicker low- $k \mathrm{GeO}_{\mathrm{x}}$ interfacial layer, resulting in higher $D_{i t}$, which is demonstrated by the distortion of the $C-V$ curves 
in the weak inversion region (see Fig. 2). The hysteresis of the $C-V$ curve is measured by sweeping in both directions and hysteresis voltages of the samples are shown in Fig. 4. The hysteresis results from the trapping and detrapping of charges at slow states or deep-level traps while sweeping back and forth over the voltage range. Obviously, a large hysteresis occurs in the LaTiON films deposited under small or large $\mathrm{Ar} / \mathrm{N}_{2}$ ratio, implying the presence of a large amount of defects in the dielectric films. Again, small hysteresis is observed for the sample deposited at an $\mathrm{Ar} / \mathrm{N}_{2}$ ratio of $24 / 6$, indicating largely reduced defects due to appropriate $\mathrm{N}$ incorporation in the LaTiON film.

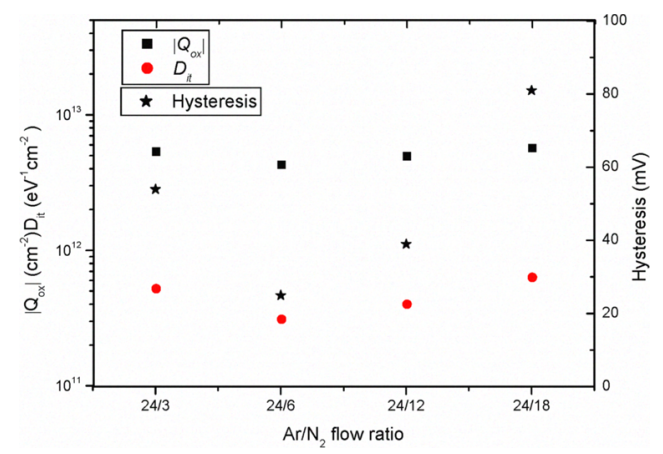

Fig. 4 Equivalent oxide-charge density $\left(Q_{o x}\right)$, interfacestate density $\left(D_{i t}\right)$ and $C-V$ hysteresis of the samples.

The gate leakage properties of the LaTiON gate-dielectric MOS capacitors deposited under different $\mathrm{Ar} / \mathrm{N}_{2}$ ratios are illustrated in Fig. 5. At a gate voltage of $1 \mathrm{~V}$, the gate leakage current density of the MOS capacitor prepared under an $\mathrm{Ar} / \mathrm{N}_{2}$ ratio of $24 / 6$ (even with the thinnest physical thickness of gate dielectric) is lower than those of the other samples. This is ascribed to its less defects at the interface and in the dielectric film, and thus less leakage paths created, due to suitable $\mathrm{N}$ incorporation in the LaTiON film for effectively suppressing the growth of low- $k \mathrm{GeO}_{\mathrm{x}}$ interfacial layer between the $\mathrm{Ge}$ substrate and gate dielectric, as mentioned above.

\section{SUMMARY}

Ge MOS capacitors with LaTiON as gate dielectric deposited at various $\mathrm{Ar} / \mathrm{N}_{2}$ ratios $(24 / 3,24 / 6,24 / 12$, and 24/18) have been fabricated, and the impacts of $\mathrm{N}$ content in the LaTiON film on the electrical properties of MOS capacitors have been investigated. A turnaround of the electrical properties with increase of $A r / \mathrm{N}_{2}$ ratio is found, with an optimal $\mathrm{Ar} / \mathrm{N}_{2}$ ratio of $24 / 6$. This implies that there exists an optimal $\mathrm{N}$ content for LaTiON used as gate dielectric, at which the deposited film can effectively suppress the growth of low- $k \mathrm{GeO}_{\mathrm{x}}$ interfacial layer due to suitable $\mathrm{N}$ incorporation in the LaTiON film, leading to less defects at the interface and in the dielectric film. In our case, the LaTiON gate-dielectric Ge MOS capacitor prepared at an $\mathrm{Ar} / \mathrm{N}_{2}$ ratio of $26 / 4$ exhibits increased $k$ value, decreased $C E T$, improved interface quality, low gate leakage current and small $C-V$ hysteresis.

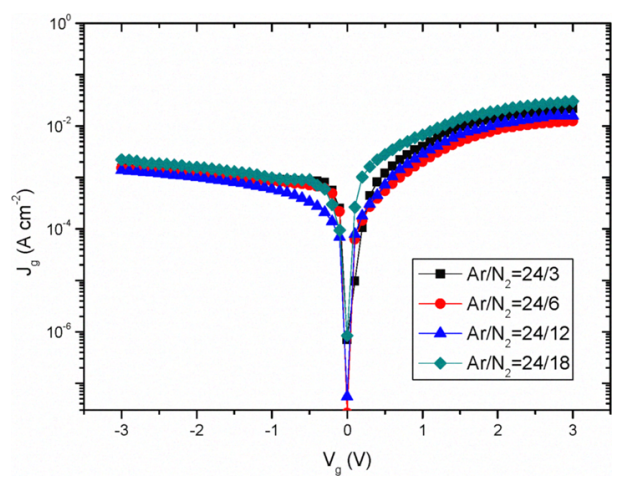

Fig. 5 Gate-leakage current density $\left(J_{g}\right)$ of the LaTiON gate-dielectric Ge MOS capacitors prepared at different $\mathrm{Ar} / \mathrm{N}_{2}$ flow ratios.

\section{ACKNOWLEDGES}

This work is financially supported by the National Natural Science Foundation of China (Grant no. 60776016), the RGC of HKSAR, China (Project No. HKU 713308E), and the University Development Fund (Nanotechnology Research Institute, 00600009) of the University of Hong Kong.

\section{REFERENCES}

[1] J. Robertson, "Band offsets of wide-band-gap oxides and implications for future electronic devices," $J$. Vac. Sci. Technol. B, vol.18, p.785, 2000.

[2] H. Iwai, S. Ohmi, S. Akama, C. Ohshima, and A. Kikuchi, "Advanced dielectric materials for sub-100nm CMOS," Tech. Dig. Int. Electron Devices Meet., p.625, 2002.

[3] S. Guha, E. Cartier, M. A. Gribelyuk, N. A. Bojarczuk, and M. C. Copel, "Atomic beam deposition of lanthanum- and yttrium-based oxide thin films for gate dielectrics," Appl. Phys. Lett., vol. 77, p. 2710, 2000.

[4] Y. H. Wu, M. Y. Yang, A. Chin, W. J. Chen, and C. M. Kwei, "Electrical characteristics of high quality $\mathrm{La}_{2} \mathrm{O}_{3}$ gate dielectric with equivalent oxide thickness of 5A," IEEE Electron Device Lett., vol. 21, p. 341, 2000.

[5] S. Y. No, D. Eom, C. S. Hwang, and H. J. Kim, "Properties of lanthanum oxide thin films deposited by cyclic chemical vapor deposition using tris (isopropyl-cyclopentadienyl) lanthanum precursor," $J$. Appl. Phys., vol.100, p. 24111, 2006.

[6] A. Dimoulas, D. P. Brunco, S. Ferrari, J. W. Seo, and Y. Panayiotatos, "Interface engineering for $\mathrm{Ge}$ metal-oxide-semiconductor devices," Thin Solid Films, vol.515, p.6337, 2007.

[7] G. Mavrou, S. Galata, P. Tsipas, A. Sotiropoulos, Y. Panayiotatos, A. Dimoulas, E. K. Evangelou, J. W. Seo, and C. Dieker, "Electrical properties of $\mathrm{La}_{2} \mathrm{O}_{3}$ and $\mathrm{HfO}_{2} / \mathrm{La}_{2} \mathrm{O}_{3}$ gate dielectrics for germanium metal-oxide-semiconductor devices," J. Appl. Phys., vol.103, p.14506, 2008.

[8] J. Song, K. Kakushima, P. Ahmet, K. Tsutsui, N. Sugii, T. Hattori, and H. Iwai, "Improvement of interfacial 
properties with interfacial layer in $\mathrm{La}_{2} \mathrm{O}_{3} / \mathrm{Ge}$ structure," Microelectron. Eng., vol. 84, p. 2336, 2007.

[9] N. Lu, H. J. Li, J. J. Peterson, and D. L. Kwong, "HfTiAlO dielectric as an alternative high- $k$ gate dielectric for the next generation of complementary metal-oxide-semiconductor devices," Appl. Phys. Lett., vol. 90, p.82911, 2007.

[10] V. V. Afanas, A. Stesmans, F. Chen, M. Li, and S. A. Campbell, "Electrical conduction and band offsets in $\mathrm{Si} / \mathrm{Hf}{ }_{\mathrm{x}} \mathrm{Ti}_{1-\mathrm{x}} \mathrm{O}_{2} /$ metal structures," J. Appl. Phys., vol.95, p.7936, 2004.

[11] C. X. Li, X. Zou, P. T. Lai, J. P. Xu, and C. L. Chan, "Effects of $\mathrm{Ti}$ content and wet- $\mathrm{N}_{2}$ anneal on Ge MOS capacitors with HfTiO gate dielectric," Microelectronics Reliability, vol.48, p.526, 2008.

[12] M. R. Visokay, J. J. Chambers, A. L. P. Rotondaro, A. Shanware, and L. Colombo, "Application of HfSiON as a gate dielectric material," Appl. Phys. Lett., vol.80, p.3183, 2002.

[13] C. H. Choi, T. S. Jeon, R. Clark, and D. L. Kwong, "Electrical properties and thermal stability of CVD $\mathrm{HfO}_{\mathrm{x}} \mathrm{N}_{\mathrm{y}}$ gate dielectric with poly-Si gate electrode," IEEE Electron Device Lett., vol.24, p. 215, 2003.

[14] P. S. Lysaght, J. Barnett, G. I. Bersuker, J. C. Woicik, D. A. Fischer, B. Foran, H. H. Tseng, and R. Jammy, "Chemical analysis of $\mathrm{HfO} 2 / \mathrm{Si}$ (100)film systems exposed to $\mathrm{NH}_{3}$ thermal processing," J. Appl. Phys., vol.101, p.24105, 2007.

[15] T. M. Pan, S. J. Hou, and C. H. Wang, "Effects of nitrogen content on the structure and electrical properties of high- $k \mathrm{NdO} x \mathrm{~N} y$ gate dielectrics," $J$. Appl. Phys., vol. 103, p.124105, 2008.

[16] L. M. Terman, "An investigation of surface states at a silicon/silicon oxide interface employing metal-oxide-silicon diodes," Solid-State Electronics, vol.5, p.285, 1962. 